Revista Destaques Acadêmicos, Lajeado, v. 10, n. 1, 2018. ISSN 2176-3070

DOI: http://dx.doi.org/10.22410/issn.2176-3070.v10i1a2018.1725

http://www.univates.br/revistas

\title{
PERCEPÇÕES DO MARKETING NAS REDES SOCIAIS DAS EMPRESAS DO VALE DO TAQUARI/RS
}

\author{
Jéssica Vanessa Doebber ${ }^{1}$, Samuel Martim de Conto², \\ Gabriel Machado Braido ${ }^{3}$
}

\begin{abstract}
Resumo: Cada vez mais os gestores estão sendo direcionados a lidar com a internet e redes sociais. $\mathrm{O}$ presente estudo tem o objetivo de analisar e identificar por meio dos consumidores, a utilização do marketing digital, com foco nas redes sociais, pelas empresas da região do Vale do Taquari/RS. Para atingir ao objetivo do estudo, a pesquisa foi realizada contendo uma etapa qualitativa e outra quantitativa. Foram realizadas 12 entrevistas em profundidade e coletados 330 questionários com estudantes da Univates. Os principais resultados apontaram que o Facebook, seguido pelo Youtube e Instagram, são as redes sociais mais acessadas pelos respondentes. Foi verificado também junto aos respondentes a boa aceitação do marketing nas redes sociais e que grande parte do público participa de ações de marketing nas redes sociais. Ao final, são apresentadas algumas sugestões de melhorias para as empresas que se utilizam das redes sociais para relacionarem-se com seus públicos alvo.
\end{abstract}

Palavras-chave: Marketing digital. Redes sociais. Vale do Taquari.

\section{Introdução}

Atualmente, conforme pesquisa da Total Retail, 40\% dos brasileiros se sentem motivados a realizar uma compra ao visitar a página da empresa nas mídias sociais, enquanto $61 \%$ levam em consideração avaliações e comentários nas redes (DIGITALKS, 2017). No Brasil, o crescimento do mercado digital se deve principalmente ao aumento do número de brasileiros com acesso à internet, pois com o crescimento da classe média brasileira, possibilitou novos consumidores com acesso a compra de computadores (LAS CASAS, 2014).

As redes sociais se tornaram uma grande oportunidade de marketing, pois deixaram de ser utilizadas somente para entretenimento, sendo

1 Graduanda em Administração pela Univates.

2 Doutor em Administração e Professor da Univates.

3 Doutorando em Administração e Professor da Univates. 
transformadas em uma plataforma eficaz de conversação com empresas, clientes e consumidores (JUNIOR; AZEVEDO, 2015). Essa comunicação e interatividade, permite que o mundo fique cada vez mais conectado e as notícias e opiniões se espalhem em uma velocidade imediata e instantânea.

Então, devido sua enorme cobertura, uma rede social pode alavancar uma empresa ao sucesso em um espaço de tempo muito curto, entretanto, é essencial ter cautela antes de vincular o seu nome a uma mídia social, pois ela permite tanto a troca de informações positivas, quanto negativas.

Dessa forma, o estudo tem como objetivo geral analisar por meio dos consumidores, a utilização do marketing através das redes sociais, por empresas do Vale do Taquari. Quanto aos específicos, objetiva-se: a) identificar as redes sociais mais acessadas; b) verificar a possibilidade de utilização do marketing digital por meio de redes sociais na região do Vale do Taquari; c) analisar como o público observa o marketing pelas redes sociais na região; d) identificar a aceitação pelo público da região quanto ao marketing digital.

Este estudo está estruturado em cinco seções: a primeira contendo a introdução; a segunda com o referencial utilizado; a terceira contendo os procedimentos metodológicos; a quarta a apresentação dos resultados das entrevistas em profundidade e do levantamento; e finalmente, as conclusões.

\section{Marketing digital nas redes sociais}

Para Limeira (2007, p. 4) "o marketing passou a ser entendido como a função empresarial que cria valor para o cliente e gera vantagem competitiva duradoura para a empresa..." Ainda segundo Limeira (2007), essa criação de valor para o cliente, é entendido como o resultado obtido com os benefícios que o produto ou serviço trará em consequência dos custos da compra para o cliente, ou seja, o valor do produto deve ser maior que o preço dele aos olhos do cliente. Já para Kotler e Keller (2006, p. 4), “o marketing envolve a identificação e a satisfação das necessidades humanas e sociais. Para defini-lo de maneira bem simples, pode-se dizer que ele 'supre necessidades lucrativamente'". Nesse sentido, também é possível definir que:

Marketing é uma atividade voltada para a conquista e manutenção lucrativas dos clientes por meio destes processos de troca, desde que atendendo as necessidades, os desejos e as expectativas visando a conquistar a fidelidade do cliente para sua empresa, produtos e serviços (HONORATO, 2004, p. 10).

Portanto marketing pode ser definido como um valor agregado ao produto ou serviço oferecido, aquilo que o cliente busca para satisfazer suas necessidades e desejos. Ele faz o trabalho de tornar o produto mais atraente aos olhos e ao bolso do cliente e para a empresa traz a vantagem de poder tornar o cliente fiel ao produto. 
Nesse sentido, marketing digital pode ser definido como "um conjunto de ações de marketing intermediadas por canais eletrônicos, como a internet, em que o cliente controla a quantidade e o tipo da informação recebida" (LIMEIRA, 2007, p. 10). E as redes sociais são uma das melhores ferramentas para o uso do marketing digital, conforme Ramalho (2010) através as redes sociais, é possível interagir e socializar, pois qualquer pessoa pode criar um cadastro e estabelecer contatos e ligações. E isso é feito pelo motivo de que é possível adicionar amigos nas redes, permitindo expandir suas ligações.

Cada vez mais é preciso inovar para que seu produto seja "visto" e na internet uma das ferramentas de marketing mais utilizada são os sites de busca, Costa (2013) diz que os sites de busca têm o intuito de aumentar a visibilidade da empresa e os usuários geralmente clicam nos primeiros três resultados da busca. Nesse sentido, Vaz (2010, p. 341) explica o conceito de links patrocinados, no Google, chamados de AdWords "são pequenos anúncios de texto que aparecem no lado direito da tela de busca no Google, e, eventualmente em uma barra amarela na parte superior no lado esquerdo". Para isso, segundo o autor, as empresas compram palavras-chave e toda vez que um usuário digital tal palavra, o anúncio é veiculado. Outras ferramentas, conforme Costa (2013), é o e-mail marketing, que é uma forma barata e eficaz de atingir os clientes atuais e potenciais, porém é preciso ter cuidado para que quem os receba, queira receber, e para que a mensagem não se torne um spam. A outra, são os banners, pequenos quadros de avisos que contêm, geralmente, elementos gráficos e uma mensagem publicitária (COSTA, 2013, p. 196). Por fim, as redes sociais, conforme Vaz (2010) é preciso utilizá-las com privacidade e transparência, é preciso estar visível em todos os grupos de interesse ou redes sociais. É preciso que a empresa tenha um representante humano, e não deixar que o perfil se torne formal e frio. Ainda, que se publique conteúdo para propagar a marca também.

A grande diferença da mídia social em comparação a jornais e revistas, é que o conteúdo não é gerado como um monólogo, é mais uma conversa informal. Outra diferença é que os usuários ainda podem desenvolver uma relação social ou de negócios nesse ambiente on-line e que pode se estender ao ambiente off-line (STRAUSS; FROST, 2012). Para Torres (2009) as mídias sociais são sites de compartilhamento de informações pelas pessoas e para as pessoas, onde o consumidor pode ser o produtor e consumidor da informação.

Para Las Casas (2014), a internet é responsável pelas grandes mudanças de comportamento na sociedade, pois com a informação, os consumidores acabam se tornando mais inteligentes na hora de comprar. Por isso Ramalho (2010) diz que a mídia social é uma forma moderna do ser humano de socializar, e buscar informações. A visibilidade das mídias sociais é amplificada pelas ferramentas de busca, como o Yahoo e o Google, principalmente porque elas geram um volume e uma diversidade de conteúdo muito maior do que a mídia convencional sonharia em produzir. Dessa forma, além de transmitirem 
sua mensagem por sua rede social, seu conteúdo aparece rapidamente para o público em geral que, frequentemente, usa as ferramentas de busca. Um exemplo claro disso é a Wikipedia, a maior enciclopédia colaborativa da Internet, que está no topo das buscas do Google com muitos dos seus verbetes (TORRES, 2009, p. 115).

Essa visibilidade das mídias sociais traz vantagens e desvantagens, ela pode ser usada por um custo muito baixo, porém ela tem vida própria, ou seja, assim que feito, é preciso interagir sempre, pois ela produz informações e comunicações espontâneas, mesmo que não queira (TORRES, 2009). Torres (2009, p. 116) ainda conclui: "Ou você participa e se envolve ou será envolvido".

Uma rede social pode ser definida como uma estrutura social formada por indivíduos, que são conectados por algumas afinidades, como amizade; parentesco; ódios/antipatias; enfim, todos os tipos de relacionamentos interpessoais (GABRIEL, 2010). Os laços interpessoais podem ser de três tipos: forte (amigos, famílias, pessoas com quem mantemos relações próximas), fracos (conhecidos, pessoas com quem mantemos relações mais superficiais) ou ausentes (pessoas que não conhecemos ou não nos relacionamos) (GABRIEL, 2010, p. 199).

Já Ramalho (2010) menciona que através as redes sociais, é possível interagir e socializar, pois qualquer pessoa pode criar um cadastro e estabelecer contatos e ligações. E isso é feito pelo motivo de que é possível adicionar amigos nas redes, permitindo expandir suas ligações.

As três redes sociais com mais usuários ativos no mundo em abril de 2017, conforme o site Statista (The Statiscs Portal), eram o Facebook, o WhatsApp e o Youtube.

Conforme Gabriel (2010), existem diversos sites de redes sociais na internet, conectando pessoas com interesses em comum (QUADRO 1).

Quadro 1 - Tipos e exemplos de redes sociais

\begin{tabular}{|l|l|}
\hline Foco principal & Rede Social \\
\hline Amizade, informação, geral & Facebook, Hi5, Sonico, Badoo, Twitter \\
\hline Apresentações & SlideShare, Scrib \\
\hline Geeks, nerds & Intellect, Connect \\
\hline Imagens & Visualize us \\
\hline Leitura, livros & Skoob \\
\hline Localização geográfica & Loopt, FourSquare \\
\hline Música & Last.fm, Blip.fm \\
\hline Notícias & Digg, Reddit \\
\hline Profissional & Linkedin \\
\hline Sonhos & MatchADream \\
\hline Vídeos & Youtube, Vimeo \\
\hline
\end{tabular}

Fonte: Adaptado de Gabriel, 2010, p. 196. 
Assim, para as empresas as redes sociais são uma forma de manter relacionamentos com os clientes, pois eles adquirem credibilidade devido muitas vezes, pelo envolvimento e conhecimento de informações via redes sociais. Porém, dentro de uma rede social também existem diversos usuários e participantes com distintas necessidades e expectativas. e a empresa precisa gerenciar ativamente para atender realmente seu público-alvo (LAS CASAS, 2014).

\section{Procedimentos metodológicos}

A pesquisa realizada possuiu uma etapa qualitativa, via entrevistas em profundidade, e outra etapa quantitativa, via levantamento (MALHOTRA, 2011; MCDANIEL; GATES, 2005; COOPER; SCHINDLER, 2016). As entrevistas em profundidade (OLIVEIRA, 2012) foram realizadas com doze estudantes da Univates, contendo sete questões abertas. As mesmas foram gravadas para posteriormente serem transcritas e interpretadas. Utilizando a análise das entrevistas e o referencial bibliográfico, foi estruturado o questionário (ZANELLA, 2009) para atender aos objetivos do estudo.

O questionário foi aplicado por meio da ferramenta online Google Forms, com envio do link via e-mail para os estudantes. Ao final, 330 responderam ao questionário. Cabe destacar que os dados coletados não retratam a totalidade da população da região do Vale do Taquari. Naturalmente os respondentes são pessoas mais jovens, estudantes da Univates, que possuem maior acesso às redes sociais.

\section{Principais resultados das entrevistas e do levantamento}

\subsection{Entrevistas em profundidade}

$\mathrm{Na}$ etapa qualitativa foram realizadas doze entrevistas, sendo sete mulheres e cinco homens, com média de idade de 23 e 24 anos (respectivamente). Os entrevistados foram questionados sobre as redes sociais que mais acessam e foram unanimes em apontar o Facebook e o Instagram. Foi verificado também que somente um dos entrevistados não acompanha nenhuma página de rede social de empresa. Todos entrevistados acreditam que o marketing digital pelas redes sociais, é uma ferramenta importante para as empresas e cinco dos respondentes já participaram de ações de marketing nas redes sociais, enquanto os outros sete nunca participaram, por falta de divulgação ou interesse.

\subsection{Levantamento}

A etapa quantitativa consiste na pesquisa descritiva com uso de coleta de dados através de questionários aplicados aos estudantes da Univates, sendo que em 2017, a Instituição possuía 12.455 alunos. Os respondentes residem da 
região do Vale do Taquari, que em 2014, conforme a Fundação de Economia e Estatística (FEE), contava com 348.435 habitantes (UNIVATES, 2017). Desta forma, foram enviados os questionários para várias turmas, sem precisão do total de alunos alcançados, e destes, 330 responderam.

Quanto à faixa etária dos respondentes, $61,8 \%$ correspondem à faixa etária de 17 a 24 anos e $26,1 \%$ de 25 a 30 anos. Somente $12,2 \%$ correspondem a faixa etária maior de 30 anos. O resultado obtido é coerente, pois os respondentes são estudantes universitários. Quanto ao número de respondentes quanto ao sexo ocorreu equilíbrio, haja vista 166 respondentes serem homens e 164 serem do sexo feminino. Como o questionário foi enviado a estudantes de cursos variados, foram 27 cursos diferentes citados. Os respondentes de Administração $(34,20 \%)$ e dos cursos de Engenharia $(28,20 \%)$ corresponderam à maioria.

Conforme a Tabela 1, a maioria das pessoas utiliza os smartphones como meio de acesso às redes sociais e a internet em geral, com 96,1\% dos respondentes. E em seguida, os notebooks com $73,6 \%$. O resultado obtido é coerente com o que é possível observar de com Gabriel (2010), ao mencionar que os consumidores estão adotando mais as tecnologias móveis e Turchi (2012) de que o número de celulares ativos no país supera o número de habitantes.

Tabela 1 - Aparelhos utilizados para acesso às redes sociais

\begin{tabular}{l|r|r}
\hline Aparelho & Quantidade & \multicolumn{1}{c}{$\%$} \\
\hline Smartphone & 317 & $96,10 \%$ \\
\hline Notebook & 243 & $73,60 \%$ \\
\hline Computador & 120 & $36,40 \%$ \\
\hline Tablet & 29 & $8,80 \%$ \\
\hline
\end{tabular}

Fonte: Elaborado pelos autores com base no levantamento.

Obs.: Esta questão permitia mais de uma resposta.

Conforme o Gráfico 1, 43\% dos respondentes acessa as redes sociais até 2 horas por dia, enquanto que $27,6 \%$ de 3 a 4 horas por dia e $25,5 \%$ mais de 5 horas por dia. Esse resultado demonstra que mais da metade dos respondentes acessa mais de 3 horas por dia. $\mathrm{O}$ resultado obtido é coerente com a realidade observada por Turchi (2012), ao afirmar que o brasileiro é um dos internautas que passa mais tempo navegando. 
Gráfico 1 - Frequência que utiliza as redes sociais.

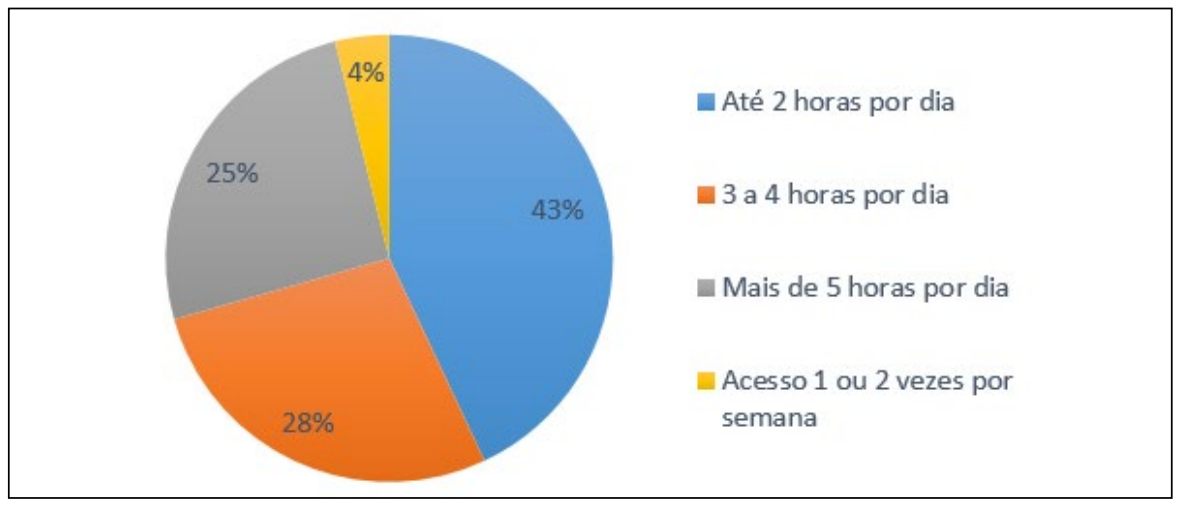

Fonte: Elaborado pelos autores com base no levantamento.

A rede social mais acessada pelos respondentes foi o Facebook, seguido pelo Youtube e o Instagram. Outras redes foram lembradas, com destaque ao WhatsApp que se trata mais de um meio de comunicação em substituição ao SMS e até mesmo ao telefone. Esse resultado tem relação com o site Statista (2017), onde são listadas as redes sociais com mais usuários ativos e o Facebook segue na primeira posição, Youtube na terceira e Instagram na sétima posição.

A seguir, foram questionados os tipos de publicidade que os respondentes costumam participar nas redes sociais, caso estes participem ou já tenham participado. Conforme a Tabela 2, é possível verificar que mais da metade dos respondentes nunca participaram de nenhuma publicidade pelas redes sociais e 121 respondentes já participaram de alguma promoção e 93 respondentes já participaram de sorteio.

Tabela 2 - Tipos de publicidade que costuma participar nas redes sociais

\begin{tabular}{l|r|r}
\hline \multicolumn{1}{c|}{ Tipo publicidade } & Quantidade & \multicolumn{1}{c}{$\%$} \\
\hline Não participo & 176 & $53,30 \%$ \\
\hline Promoção & 121 & $36,70 \%$ \\
\hline Sorteio & 93 & $28,20 \%$ \\
\hline Oferta & 58 & $17,60 \%$ \\
\hline Concurso cultural & 9 & $2,70 \%$ \\
\hline
\end{tabular}

Fonte: Elaborado pelos autores com base no levantamento.

Obs.: Esta questão permitia mais de uma resposta.

Quanto ao setor de atuação das empresas do Vale do Taquari que os respondentes já observaram a utilização do marketing por meio das redes 
sociais, é possível verificar que o setor de vestuário é o que mais utiliza as redes sociais para marketing, em seguida automóveis e alimentação (TABELA 3).

Tabela 3 - Setor de atuação de empresas do Vale do Taquari que utilizam as redes sociais para o marketing

\begin{tabular}{l|r}
\hline \multicolumn{1}{c|}{ Setor atuação } & \multicolumn{2}{c}{ Quantidade } \\
\hline Roupas & 242 \\
\hline Automóveis & 180 \\
\hline Alimentação & 178 \\
\hline Sapatos & 171 \\
\hline Móveis e eletrodomésticos & 137 \\
\hline Não vi nenhuma & 32 \\
\hline Outros & 16 \\
\hline
\end{tabular}

Fonte: Elaborado pelos autores com base no levantamento.

Obs.: Esta questão permitia mais de uma resposta.

Conforme o Gráfico 2, o Facebook é a rede social mais utilizada pelas empresas do Vale do Taquari, correspondendo a $86,1 \%$ dos respondentes. O Instagram foi mencionado por $35,8 \%$ dos respondentes, enquanto que o Twitter e o Youtube ficaram com um percentual pequeno, indicando a pouca utilização dessas redes sociais pelas empresas da região. Ainda 11,8\% dos respondentes não curte e nem segue nenhuma empresa da região nas redes sociais.

Gráfico 2 - Redes sociais de empresas da região que curte ou segue

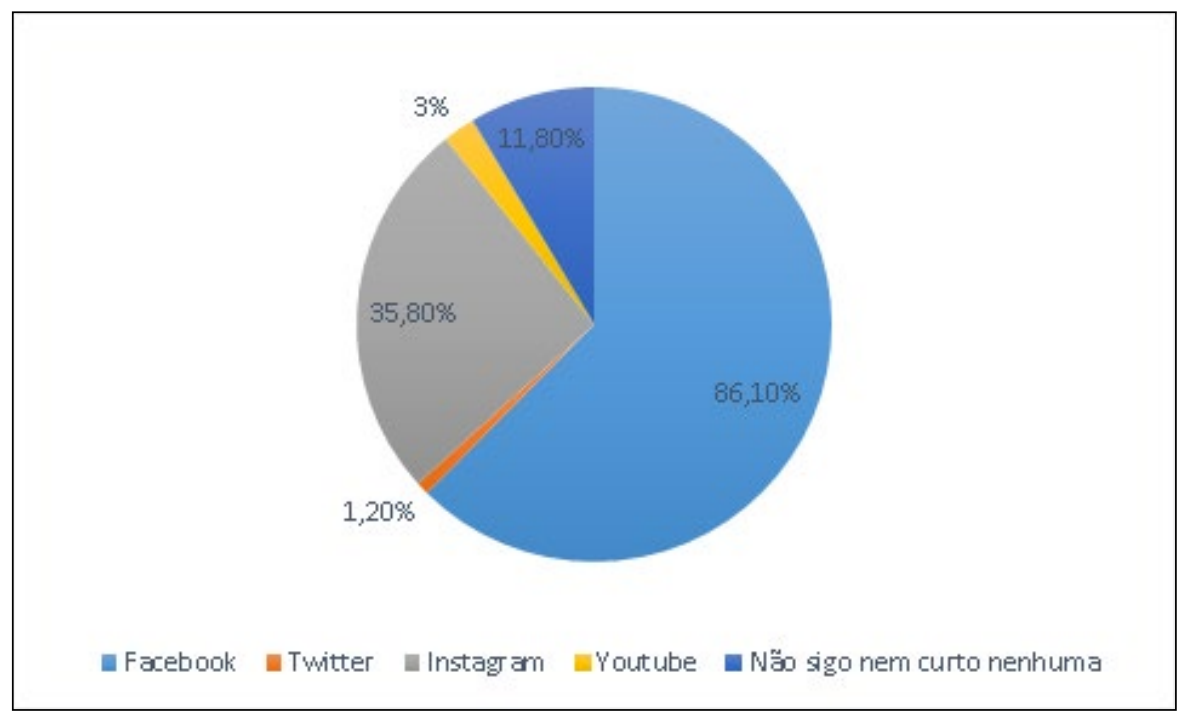

Fonte: Elaborado pelos autores com base no levantamento. 
Quanto à participação em ações de marketing em redes sociais de empresas da região, conforme o Gráfico 3, 53,6\% dos respondentes nunca participaram de nenhuma ação de marketing realizada por empresas da região, enquanto os demais respondentes afirmaram já terem participado, destacandose as promoções e sorteios.

Gráfico 3 - Participação de ações de marketing em redes sociais de empresas da região

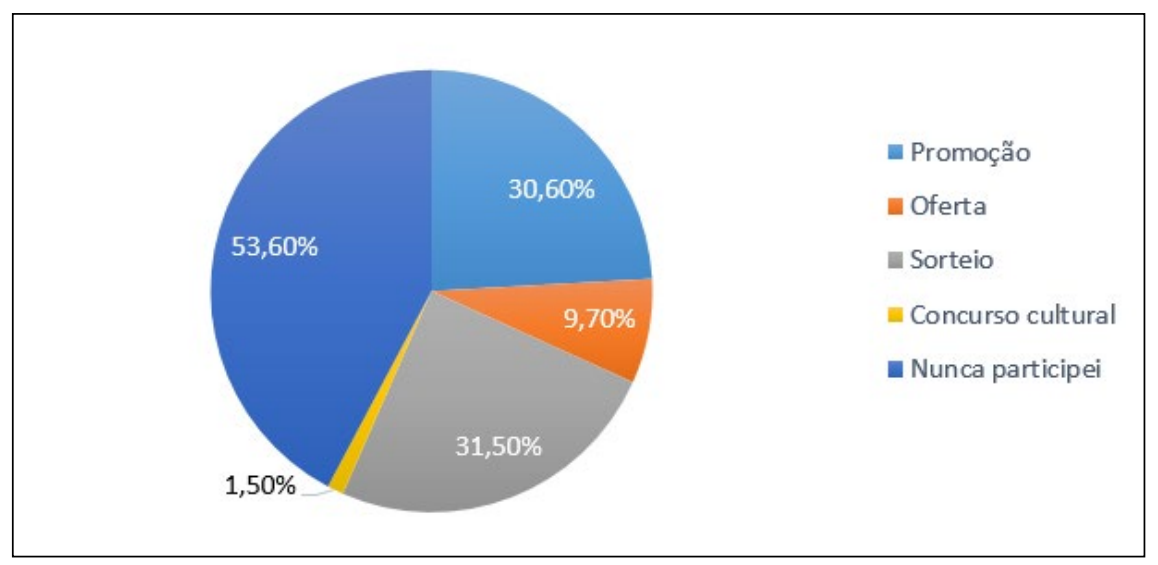

Fonte: Elaborado pelos autores com base no levantamento.

O bloco de questões a seguir, referem-se à concordância (ou não) das redes sociais para sociedade e para as organizações.

Conforme a Tabela 4, 61,8\% dos respondentes concorda em parte que as redes sociais influenciam as opiniões das pessoas, enquanto $29,1 \%$ concorda totalmente. Somente 3\% discordaram e 6,1\% não concorda e nem discorda. Esse resultado reflete a atualidade onde as redes sociais são formadoras de opiniões, inclusive existem pessoas consideradas "digital influencier". E este resultado está de acordo com o que Vaz (2010) menciona, que quanto mais pessoas se associam, mais conteúdos se constroem, espalham e geram comentários.

Tabela 4 - Influência das redes sociais nas opiniões das pessoas

\begin{tabular}{l|r|c}
\hline Concordância & Quantidade & $\%$ \\
\hline Concordo totalmente & 96 & $29,10 \%$ \\
\hline Concordo em parte & 204 & $61,80 \%$ \\
\hline Não concordo e nem discordo & 20 & $6,10 \%$ \\
\hline Discordo em parte & 9 & $2,70 \%$ \\
\hline Discordo totalmente & 1 & $0,30 \%$ \\
\hline
\end{tabular}

Fonte: Elaborado pelos autores com base no levantamento. 
A grande maioria dos respondentes concorda que as redes sociais servem como uma boa via de divulgação pelas empresas (TABELA 5). Somente duas pessoas discordam em parte e uma pessoa não concorda e nem discorda. O resultado obtido alinhado com o que Las Casas (2014) menciona, de que as redes sociais são uma boa forma de manter relacionamento com os clientes, se bem utilizada.

Tabela 5 - Redes sociais como uma boa via de divulgação em marketing

\begin{tabular}{l|r|r}
\hline Concordância & Quantidade & $\%$ \\
\hline Concordo totalmente & 220 & $66,70 \%$ \\
\hline Concordo em parte & 107 & $32,40 \%$ \\
\hline Não concordo e nem discordo & 1 & $0,30 \%$ \\
\hline Discordo em parte & 2 & $0,60 \%$ \\
\hline Discordo totalmente & 0 & $0,00 \%$ \\
\hline
\end{tabular}

Fonte: Elaborado pelos autores com base no levantamento.

Conforme a Tabela 6, os respondentes foram bem dispersos nas afirmativas se compartilham publicidades nas redes sociais, o que indica que ainda não é uma prática muito utilizada. A maior porcentagem foi de 33,3\% da opção concordo em parte.

Tabela 6 - Compartilha publicidades para outras pessoas

\begin{tabular}{l|r|c}
\hline Concordância & Quantidade & $\%$ \\
\hline Concordo totalmente & 37 & $11,20 \%$ \\
\hline Concordo em parte & 110 & $33,30 \%$ \\
\hline Não concordo e nem discordo & 84 & $25,50 \%$ \\
\hline Discordo em parte & 38 & $11,50 \%$ \\
\hline Discordo totalmente & 61 & $18,50 \%$ \\
\hline
\end{tabular}

Fonte: Elaborado pelos autores com base no levantamento.

Conforme Tabela 7, 41,2\% dos respondentes concorda em parte que participaria de campanhas de marketing digital de empresas da região, o que demonstra que a maioria dos respondentes divulgaria essas ações, seguido por $26,1 \%$ ao apontarem a opção não concorda e nem discorda. 
Tabela 7 - Participaria e compartilharia campanhas de marketing de empresas da região em suas redes sociais

\begin{tabular}{l|r|c}
\hline Concordância & Quantidade & $\%$ \\
\hline Concordo totalmente & 35 & $10,60 \%$ \\
\hline Concordo em parte & 136 & $41,20 \%$ \\
\hline Não concordo e nem discordo & 86 & $26,10 \%$ \\
\hline Discordo em parte & 27 & $8,20 \%$ \\
\hline Discordo totalmente & 46 & $13,90 \%$ \\
\hline
\end{tabular}

Fonte: Elaborado pelos autores com base no levantamento.

A seguir (TABELA 8) os respondentes opinaram se acreditam que as redes sociais são um espaço bem utilizado pelas empresas da região. Para 52,1\% dos respondentes concordam em parte que as empresas da região utilizam bem as redes sociais, enquanto que $22,7 \%$ não concordam e nem discordam. Esse resultado demonstra que os respondentes visualizam que as empresas ainda precisam melhorar essa questão.

Tabela 8 - Redes sociais são bem utilizadas pelas empresas da região

\begin{tabular}{l|r|c}
\hline Concordância & Quantidade & $\%$ \\
\hline Concordo totalmente & 24 & $7,30 \%$ \\
\hline Concordo em parte & 172 & $52,10 \%$ \\
\hline Não concordo e nem discordo & 75 & $22,70 \%$ \\
\hline Discordo em parte & 46 & $13,90 \%$ \\
\hline Discordo totalmente & 13 & $3,90 \%$ \\
\hline
\end{tabular}

Fonte: Elaborado pelos autores com base no levantamento.

Na Tabela 9 são apresentados os resultados se, na opinião dos respondentes, as empresas deveriam utilizar mais as redes sociais. A grande maioria dos respondentes acredita que as empresas da região deveriam utilizar mais o espaço que as redes sociais fornecem para o marketing. 
Tabela 9 - As empresas deveriam utilizar mais as redes sociais como um espaço para marketing

\begin{tabular}{l|r|c}
\hline Concordância & Quantidade & $\%$ \\
\hline Concordo totalmente & 169 & $51,20 \%$ \\
\hline Concordo em parte & 123 & $37,30 \%$ \\
\hline Não concordo e nem discordo & 34 & $10,30 \%$ \\
\hline Discordo em parte & 4 & $1,20 \%$ \\
\hline Discordo totalmente & 0 & $0,00 \%$ \\
\hline
\end{tabular}

Fonte: Elaborado pelos autores com base no levantamento.

Finalizando, na Tabela 10 observa-se se os respondentes acreditam que o público da região tenha uma boa aceitação para o marketing através das redes sociais. Conforme os resultados, a grande maioria concorda que o público da região tem boa aceitação para o marketing pelas redes sociais, sendo que $30,3 \%$ concorda totalmente e $57,6 \%$ concorda em parte. Somente dez pessoas discordaram (em parte ou totalmente).

Tabela 10 - Público da região têm boa aceitação para o marketing através das redes sociais

\begin{tabular}{l|r|c}
\hline Concordância & Quantidade & \% \\
\hline Concordo totalmente & 100 & $30,30 \%$ \\
\hline Concordo em parte & 190 & $57,60 \%$ \\
\hline Não concordo e nem discordo & 30 & $9,10 \%$ \\
\hline Discordo em parte & 9 & $2,70 \%$ \\
\hline Discordo totalmente & 1 & $0,30 \%$ \\
\hline
\end{tabular}

Fonte: Elaborado pelos autores com base no levantamento.

A seguir são apresentadas as principais conclusões do estudo realizado, relacionado os objetivos propostos aos resultados encontrados.

\section{Conclusões}

O presente estudo foi realizado com o objetivo principal de analisar por meio dos consumidores, a utilização do marketing através das redes sociais, por empresas do Vale do Taquari. A partir da análise dos resultados da pesquisa, é possível ter uma visão geral da utilização que as empresas fazem das redes sociais para o marketing. Além disso, o estudo revela melhorias que podem ser adotadas e aplicadas pelas empresas, frente ao que os consumidores responderam. 
Quanto aos objetivos específicos, o primeiro consistiu em identificar as redes sociais mais acessadas. Conforme a pesquisa realizada, foi verificado que o Facebook é a rede social mais acessada por $95 \%$ dos respondentes, seguida pelo Youtube com 70\% e Instagram com 69\%. Através dessas respostas, é possível identificar as redes que mais podem ser investidas para ações de marketing.

O segundo objetivo específico consistiu em verificar a possibilidade de utilização do marketing digital por meio de redes sociais na região do Vale do Taquari. Para isso, foi identificado que 51,8\% dos respondentes participaria e compartilharia ações de marketing de empresas da região. Enquanto 88,5\% dos respondentes concorda que as empresas da região deveriam utilizar mais as redes sociais para o marketing. E ainda, $87,9 \%$ concorda que o público da região tem boa aceitação para o marketing digital. Portanto, através dessas respostas, é possível afirmar que há possibilidades de utilização do marketing pelas redes sociais nas empresas do Vale do Taquari.

O terceiro objetivo específico consistiu em analisar como o público observa o marketing pelas redes sociais na região. Através da pesquisa, foi identificado que $59,4 \%$ dos consumidores concordam que as redes sociais são bem utilizadas pelas empresas da região, enquanto $22,7 \%$ é neutro e $17,8 \%$ discorda. E ainda, $88,5 \%$ acredita que as empresas da região deveriam utilizar mais esse espaço. Logo, é possível verificar pelos resultados, que os respondentes observam que as empresas utilizam bem esse espaço, porém poderiam utilizar mais.

O quarto e último objetivo específico consistiu em identificar a aceitação pelo público da região quanto ao marketing digital. Conforme os resultados apresentados pela pesquisa, $87,9 \%$ concorda que o público da região tem boa aceitação para o marketing através das redes sociais, enquanto $9,1 \%$ é neutro e apenas $11,8 \%$ discorda.

Em suma, pode-se afirmar que o marketing através das redes sociais não é mais uma novidade para as empresas, inclusive para as empresas da região do Vale do Taquari que já utilizam, conforme identificado pelos resultados obtidos. Obviamente, ainda é preciso explorar mais os benefícios que esse espaço pode alcançar para aumentar o relacionamento entre clientes e organizações.

\section{Referências}

COOPER, Donald R; SCHINDLER, Pamela S. Métodos de pesquisa em

administração. Tradução Scientific Linguagem Ltda, Iuri Duquia Abreu. 12. Ed. Porto Alegre: AMGH, 2016.

COSTA, Gilberto Cézar Gutierrez da. Negócios eletrônicos: uma abordagem estratégica e gerencial [livro eletrônico]. Curitiba: InterSaberes, 2013.

DIGITALKS. Pesquisa revela mudança em hábitos de compra dos consumidores brasileiros. 2017. Disponível em: <https:/ /digitalks.com.br/indicadores-do- 
mercado/pesquisa-revela-mudanca-em-habitos-de-compra-dos-consumidoresbrasileiros/> Acesso em: 24 nov. 2017.

FUNDAÇÃO DE ECONOMIA E ESTATÍSTICA. Corede Vale do Taquari, 2015. Disponível em:< http://www.fee.rs.gov.br/perfil-socioeconomico/coredes / detalhe/ corede=Vale+do+Taquari $>$.Acesso em: 11 mar de 1017.

GABRIEL, Martha. Marketing na era digital. São Paulo: Novatec Editora, 2010.

HONORATO, Gilson. Conhecendo o marketing. Barueri, SP: Manole, 2004.

JUNIOR, Achiles Batista Ferreira; AZEVEDO, Ney Queiroz de. Marketing digital: uma análise do mercado 3.0 [livro eletrônico]. Curitiba: InterSaberes, 2015.

KOTLER, Philip; KELLER, Kevin Lane. Administração de marketing. Tradução Mônica Rosenberg, Brasil Ramos Fernandes, Cláudia Freire. Revisão técnica Dilson Gabriel dos Santos. 12.ed. São Paulo: Pearson Prentice Hall, 2006.

LAS CASAS, Alexandre Luzzi. Cocriação de valor: conectando a empresa com os consumidores através das redes sociais e ferramentas colaborativas. São Paulo: Atlas, 2014.

LIMEIRA, Tania M. Vidigal. E-marketing. 2.ed. São Paulo: Saraiva, 2007.

MALHOTRA, N.. Pesquisa de marketing: foco na decisão. 3. ed. São Paulo: Pearson, 2011.

MCDANIEL, Carl D.; GATES, Roger. Fundamentos de pesquisa de marketing. Tradução Dalton Conde de Alencar. Revisão técnica Mônica Zaidan Rossi. 2. Ed. Rio de Janeiro: LTC, 2005.

OLIVEIRA et al. Entrevista "em profundidade" na pesquisa qualitativa em administração: pistas teóricas e metodológicas. SIMPOI-Fundação Getúlio Vargas. São Paulo: 2012. Disponível em <http:/ / www.simpoi.fgvsp.br/arquivo/2012/ artigos/e2012_t00259_pcn02976.pdf> Acesso em 25 de maio de 2017.

RAMALHO, Jose Antônio. Mídias sociais na prática. São Paulo: Elsevier, 2010.

STATISTA. Disponível em: <https:/ / www.statista.com/statistics / 272014/globalsocial-networks-ranked-by-number-of-users / > Acesso em 29 de abril de 2017.

STRAUSS, Judy; FROST, Raymond. E-marketing. Tradução Regina Claudia Loverri. São Paulo: Pearson Prentice Hall, 2012.

TORRES, Claudio. A bíblia do marketing digital: tudo o que você queria saber sobre marketing e publicidade na internet e não tinha a quem perguntar. São Paulo: Novatec Editora, 2009. 
TURCHI, Sandra R. Estratégias de marketing digital e e-commerce. São Paulo: Atlas, 2012.

UNIVATES. Vale do Taquari. Disponível em < http:/ / www.univates.br/ institucional/vale-do-taquari> Acesso em 29 abr. 2017.

VAZ, Conrado Adolpho. Google marketing: o guia definitivo de marketing digital. São Paulo: Novatec Editora, 2010.

ZANELLA, Liane Carly Hermes. Metodologia de estudo e de pesquisa em administração. UFSC 2009. Disponível em: <http:/ /200.129.241.123/arquivos/ Fasciculo_Metodologia_TC.pdf> Acesso em: 16 mai. 2017. 